\title{
Stimulation of Melanogenesis by Cholecalciferol in Gultured Human Melanocytes : A Possible Mechanism Underlying Pigmentation after Ultraviolet Irradiation
}

\author{
Yasushi Tomita, Masafumi Funushima* and Hachiro \\ TAGAMI \\ Department of Dermatology, Tohoku University School of \\ Medicine, Sendai $980{ }^{*}$ Chugai Pharmaceutical Co., Tokyo \\ 360
}

Tomita, Y., Funushima, M. and Tagami, H. Stimulation of Melanogenesis by Cholecalciferol in Cultured Human Melanocytes: A Possible Mechanism Underlying Pigmentation after Ultraviolet Irradiation. Tohoku J, exp. Med., 1986, 149(4), 451-452 - An increase in the amount of tyrosinase was demonstrated in the cultured human melanocyte after 6-day culturing with cholecalciferol (vitamin $\mathrm{D}_{3}$ ) by increased intensity of the immunofluorescent staining using monoclonal antibody against tyrosinase. Furthermore, the melanocytes became more dendritic as noted in those in the skin after the irradiation of ultraviolet. However, 7-dehydrocholesterol (pro-vitamin $\mathrm{D}_{3}$ ) or $1 \alpha, 25$-dihydroxy-vitamin $\mathrm{D}_{3}$ (activated vitamin $\mathrm{D}_{3}$ ) did not induce any such effect on the cultured human melanocytes. Since cholecalciferol is known to be photo-chemically converted by the ultraviolet irradiation from pro-vitamin $\mathrm{D}_{3}$ produced in the skin, the so-far-unknown mechanism of human skin pigmentation after the ultraviolet irradiation may be partly explained by this stimulating effect of vitamin $\mathrm{D}_{3}$ on the melanocytes. cholecalciferol ; melanocyte; tyrosinase ; ultraviolet light; vitamin $\mathrm{D}_{3}$

The basic mechanism underlying human skin darkening induced by ultraviolet (UV) irradiation has not been elucidated yet. Oikawa and Nakayasu (1974) noted cholecalciferol (vitamin $\mathrm{D}_{3}$ ) increased the tyrosinase activity in the cultured cells of B-16 mouse melanoma. Since it was known that cholecalciferol could be converted photochemically from 7 dehydrocholesterol (pro-vitamin $\mathrm{D}_{3}$ ) by UV irradiation, they suggested that cholecalciferol might also play a physiological role in photo-induced melanogenesis in the human skin. Recently we have developed a simple but reliable technique to culture numerous normal melanocytes from the roof of a suction blister raised on human skin. By using this melanocyte culture method and monoclonal antibody against tyrosinase, we have examined whether or not vitamin $\mathrm{D}_{3}$ increases the amount of tyrosinase in the human melanocytes.

Received May 26, 1986 ; accepted for publication June 24, 1986.

This report was supported in part by grants from the Ministry of Education, Science and Culture of Japan (No. 60570453) and the Japan Lydia O'Leary Foundation, Tokyo. 
TABLE 1. The intensity of FITC in immunofluorescent staining of human melanocytes cultured in the presence of various vitamin $D_{3}$

\begin{tabular}{lccr}
\hline \multirow{2}{*}{ Treatment } & $\begin{array}{c}\text { Number of } \\
\text { cells } \\
\text { examined }\end{array}$ & \multicolumn{2}{l}{$\begin{array}{l}\text { Relative fluorescent } \\
\text { intensity at } 520 \mathrm{~nm}\end{array}$} \\
\cline { 3 - 4 } & 100 & 28.6 & 6.8 \\
\hline None & 100 & 27.2 & 6.4 \\
$1.3 \mu \mathrm{M}$ 7-dehydrocholesterol & 100 & $39.9^{*}$ & 11.8 \\
$1.3 \mu \mathrm{M}$ cholecalciferol & 100 & 27.1 & 7.3 \\
\hline
\end{tabular}

${ }^{*}$ None vs cholecalciferol, $p<0.01$.

The culture method of human melanocytes from the roof of suction blister is as described previously (Tomita et al. 1985a). Melanocytes were cultured in Eagle's MEM with $10 \%$ fetal bovine serum and $10 \mathrm{ng} / \mathrm{ml}$ phorbol 12 -myristates 13 -acetate (PMA) for the first six days and then the medium was changed to PMA-free medium. After three day-culture without PMA, vitamin $\mathrm{D}_{3}$ or its various derivatives were added to the culture medium and the culture was further continued for 6 days. Immunofluorescent staining of the cultured melanocytes was then carried out according to the method described previously using monoclonal antibody to tyrosinase (Tomita et al. 1985b) and fluorescein isothiocyanate (FITC)-conjugated second antibody to the monoclonal antibody (TAGO Inc., CA, USA). The intensity of fluorescence of FITC in each melanocyte was measured at $520 \mathrm{~nm}$ by Olympus multimicrospectrophotometer (model MMSP). PMA, 7-dehydrocholesterol and cholecalciferol were obtained from Sigma Chemical Company (St. Louis, MO, USA) and $1 \alpha$, 25-dihydroxy-vitamin $\mathrm{D}_{3}$ was from Chugai Pharmaceutical Co. (Tokyo).

Intensity of fluorescence in the stained melanocytes increased only in those cultured with $1.3 \mu \mathrm{M}$ of cholecalciferol (Table 1). The majority of these melanocytes extended their dendrites. In contrast, $1.3 \mu \mathrm{M}$ of 7-dehydrocholesterol and 1 or $10 \mathrm{nM}$ of $1 \alpha$, 25-dihydroxyvitamin $\mathrm{D}_{3}$ did not produce any effects either on the fluorescence intensity or on the cell morphology. $1 \alpha, 25$-Dihydroxy-vitamin $\mathrm{D}_{3}$ at the concentration of $50 \mathrm{nM}$ or higher was rather toxic to the melanocytes. Photochemically-induced cholecalciferol is enzymatically converted to activated vitamin $\mathrm{D}_{3}$ such as $1 \alpha, 25$-dihydroxy-vitamin $\mathrm{D}_{3}$ in the kidney and/ or in the liver to regulate the concentration of calcium in the body fluid. The results of our study present for the first time the direct evidence that cholecalciferol has a stimulatory effect on the melanogenesis in the human malanocytes which is presumed to take place in photo-induced skin pigmentation.

\section{References}

1) Oikawa, A. \& Nakayasu, M. (1974) Stimulation of melanogenesis in cultured melanoma cells by calciferols. FEBS letters, 42, 32-35.

2) Tomita, Y., Yamamoto, H., Sato, C. Takeuchi, T. \& Tagami, H. (1985a) Efficient culturing of human melanocytes from suction blisters. Tohoku J. exp. Med., 147, 219-220.

3) Tomita, Y., Montague, P.M. \& Hearing, V.J. (1985b) Anti-T4-tyrosinase monoclonal antibodies-specific markers for pigmented melanocytes. $J$. invest. Derm., 85, 426-430. 